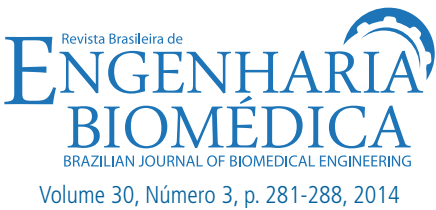

Original Article

DOl: http://dx.doi.org/10.1590/1517-3151.0252

\title{
A mass-spring model of the auditory system in otosclerosis
}

\author{
Lygia Bueno Fragoso*, Max de Castro Magalhães, Estevam Barbosa de Las Casas, \\ Juliana Nunes Santos, Alessandra Terra Vasconcelos Rabelo, Rafaella Cristina Oliveira
}

\begin{abstract}
Introduction: This paper aims to describe a model to simulate otosclerosis using a mass-spring model and to correlate the results with the clinical and audiological data on the disease. Methods: A mass-spring model was used to represent the behavior of the auditory system simulating otosclerosis. The model consisted of six masses (air volume in the external auditory canal; tympanic membrane; malleus; incus; stapes, and cochlear fluid), springs and dashpots simulating the supporting ligaments and muscles. The parameters to simulate the disease were obtained from the literature; stapedial annular ligament stiffness was increased by 10 -fold and to 100 -fold and stapes mass increased by 5 -fold. Results: There was a decrease in stapes displacement in the lower frequencies when the stiffness of the stapedial annular ligament was increased. It was also found a reduction in stapes displacement in the higher frequencies with increased stapes mass. Conclusions: The increased stiffness of the stapedial annular ligament can be an indication of early stage disease, whereas increased bone growth suggests disease progression. The results of the simulation are in agreement with the clinical and audiological disease and support the need for further study of the stapedial annular ligament to find ways to evaluate its functioning and thus enable early detection of hearing losses caused by changes in that structure.
\end{abstract}

Keywords Biomechanics, Otosclerosis, Hearing.

\section{Introduction}

Biomechanical studies of human hearing have been widely reported in the literature (Dai et al., 2007; Feng and Gan, 2002, 2004; Gan et al., 2004, 2007, 2010; Garbe et al., 2010; Huber et al., 2003; Koike et al., 2002; Liu et al., 2009; Sun et al., 2002; Zhao et al., 2009). The main reason for this interest is that the ear is a key sensory organ in communication, which is a basic human need (Bertachini and Gonçalves, 2002).

Hearing loss can compromise language and cognitive development, the intelligibility of the spoken message, and have an impact on an individual's social life. Therefore, early diagnosis of hearing impairment is of paramount importance (Roslyn-Jensen, 1996). In this context, the need to better understand hearing function, simulate the pathologies of the ear, anticipate the consequences of ear diseases, and conceive potential modalities of treatment has prompted biomechanical studies of this complex sensory system.

The function of the human auditory system is to transform the mechanical sound wave collected from the external environment into electrical impulses that are sent to the brain, where the auditory information is interpreted (Hungria, 1988; Zemlin, 2005). Hearing loss occurs when an alteration is present in any segment of the auditory system; one causative factor of such alterations is otosclerosis.

Otosclerosis is a hereditary, degenerative disease of the otic capsule and inner ear walls, with foci of new bone formation and increased local vascularization. The second most frequently involved site is the area of the oval window and the stapedial footplate (Beales, 1987). The characteristic changes of otosclerosis in the auditory system are increased stiffness of the stapedial annular ligament (Dai et al., 2009; Feng and Gan, 2004; Huber et al., 2003; Min et al., 2010) and abnormal bone growth (Brookler, 2008; Frost, 1962; Hungria, 1988; Miller and Schein, 2005; Min et al., 2010; Vicente et al., 2004).

Typically, the symptoms of otosclerosis are hearing loss, tinnitus, and vertigo, or a combination of these; symptoms may vary depending on the course of the disease (Hungria, 1988; Menger and Tange, 2003). From the audiometric point of view, the course of otosclerosis can be divided into four grades of severity: I, II, III, and IV. Grade I corresponds to the onset of the disease and is marked by an ascending audiometric curve with a more prominent loss for lowpitched sounds, which does not occur beyond $60 \mathrm{~dB}$. In grade II, the audiometric curve is more horizontal, showing an initial decrease in the perception of highpitched sounds. In grade III, audiometry shows a descending curve and hearing loss may reach up to $90 \mathrm{~dB}$, predominantly for high-pitched sounds. In grade IV, a lack of response for high-pitched sounds is already observable (Hungria, 1988).

Biomechanical studies on normal hearing have been widely reported in the literature (Dai et al., 2007; Feng and Gan, 2002; Gan et al., 2004, 2007, 2010; Huber et al., 2003; Liu et al., 2009; Sun et al., 2002; Zhao et al., 2009). However, the same is not true for the simulation of the auditory system pathologies. 
Regarding otosclerosis, there are few biomechanical studies of the ear simulating the disease. A onedimensional physical model of the auditory system constituted by six masses suspended by springs and dashpots showed a reduction in stapes displacement and, consequently, in auditory response, after a 10 -fold increase in the stiffness of the stapedial annular ligament-one of the features of otosclerosis (Feng and Gan, 2004). In another study using the finite element method, a three-dimensional (3-D) model of the ear was developed and two simulation groups were created: one with otosclerosis and the other with otosclerosis associated with fixation of the anterior mallear ligament. The first group had increased stapedial annular ligament stiffness while the second also had anterior mallear ligament stiffness. The results revealed a dramatic reduction in middle ear sound transfer gain, especially at low frequencies (Huber et al., 2003).

There are other studies, but these only mention the possibility of simulating otosclerosis and other pathological conditions using a biomechanical model of the ear (Costa, 2008; Garbe et al., 2010; Kelly et al., 2003).

The aim of the present study was to use a previously validated (Feng and Gan, 2004) one-dimensional mass-spring model to simulate otosclerosis, and compare the results with the audiological findings and different grades of the disease

\section{Methods}

The discrete mass-spring model of the auditory system (Figure 1) is intended to simulate the behavior of normal hearing and when affected by otosclerosis.

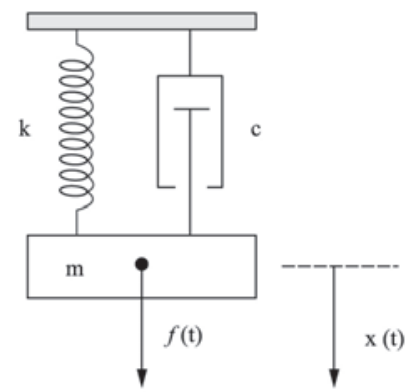

Figure 2. Diagram of a mass-spring model simulating the auditory system.
In a damped mass-spring system, the equation of motion can be represented as

$$
\begin{aligned}
& m \ddot{x}+c \dot{X}+k x=f(t) \\
& x=\vec{X} e^{j w t} \\
& \dot{x}=j w \vec{X} e^{j w t} \\
& \ddot{X}=-w^{2} \vec{X} e^{j w t}
\end{aligned}
$$

where $m$ is the mass, $c$ is the damping parameter, $k$ is the stiffness, $x$ is the displacement, $\ddot{x}$ is the acceleration, $\dot{x}$ is the velocity of the system matrices, and $f(\mathrm{t})$ denotes an externally applied force.

Therefore, a mass-spring system includes the basic components of an oscillating system: mass, spring (stiffness), and damping. When a force acts on the system, the resulting equations of motion are

$$
\begin{aligned}
& \omega=2 \pi f \\
& \omega=\sqrt{\frac{k}{m}} \\
& f=\frac{1}{2 \pi} \sqrt{\frac{k}{m}}
\end{aligned}
$$

where $\omega$ is the angular frequency of the system in radians per second and $f$ is the frequency in $\mathrm{Hz}$.

In the present study, the mass-spring model of the auditory system was composed of six masses - M1, M2, M3, M4, M5, and M6 - representing, respectively, the masses of the external auditory canal, tympanic membrane, malleus, incus, stapes, and cochlear fluid. The mass of the external auditory canal corresponds to the volume of air that fills the canal. Masses M1, M2, M3, M4, M5, and M6 are suspended by massless springs and dashpots that simulate the ligaments, supporting muscles, and interfaces, and are represented in Figure 2, respectively, by K1, C1, K2, C2, K3, C3, K5, C5, K6, C6, K8, C8, C4, C7, C9, C10. Element $\mathrm{K} 8$ represents the stapedial annular ligament, which will be used later to simulate otosclerosis. The mathematical model in this study was adapted from a model used by Feng and Gan, and the parameters of mass, stiffness, and damping used in the present discrete mass-spring model were obtained directly from anatomical data found in the literature (Feng and Gan, 2004), as shown in Tables 1 and 2.

According to Equation 1, the following matrices for a damped mass-spring system are obtained:

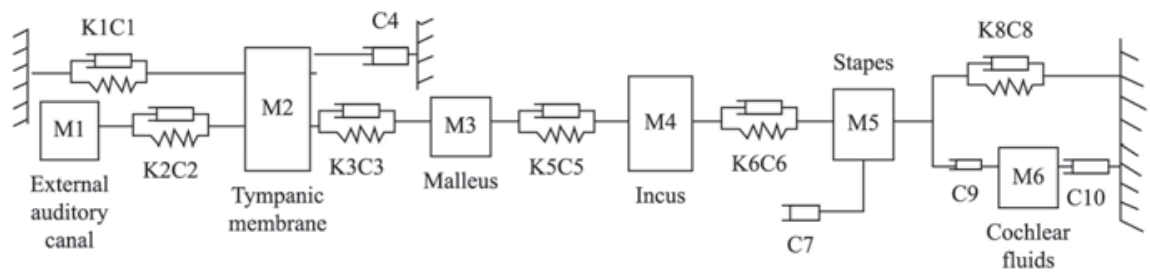

Figure 1. Diagram of a damped mass-spring model subjected to a force $f(t)$. 
$[\mathrm{m}]=\left[\begin{array}{cccccc}m 1 & 0 & 0 & 0 & 0 & 0 \\ 0 & m 2 & 0 & 0 & 0 & 0 \\ 0 & 0 & m 3 & 0 & 0 & 0 \\ 0 & 0 & 0 & m 4 & 0 & 0 \\ 0 & 0 & 0 & 0 & m 5 & 0 \\ 0 & 0 & 0 & 0 & 0 & m 6\end{array}\right]$

$[c]=\left[\begin{array}{cccccc}c 2 & -c 2 & 0 & 0 & 0 & 0 \\ -c 2 & c 1+c 2+c 3 & -c 3 & 0 & 0 & 0 \\ 0 & -c 3 & c 3+c 4+c 5 & -c 5 & 0 & 0 \\ 0 & 0 & -c 5 & c 5+c 6+c 7 & -c 6 & 0 \\ 0 & 0 & 0 & -c 6 & c 6+c 8+c 9 & -c 9 \\ 0 & 0 & 0 & 0 & -c 9 & c 9+c 10\end{array}\right]$

$[k]=\left[\begin{array}{cccccc}k 2 & -k 2 & 0 & 0 & 0 & 0 \\ -k 2 & k 1+k 2+k 3 & -k 3 & 0 & 0 & 0 \\ 0 & -k 3 & k 3+k 5 & -k 5 & 0 & 0 \\ 0 & 0 & -k 5 & k 5+k 6 & -k 6 & 0 \\ 0 & 0 & 0 & -k 6 & k 6+k 8 & 0 \\ 0 & 0 & 0 & 0 & 0 & 0\end{array}\right]$

where [m] is the mass matrix, [c] is the damping matrix, and $[\mathrm{k}]$ is the cstiffness matrix.

From Equations 1, 2, 3, and 4 the following equation can be obtained:

$$
x=-\omega^{2}(l) \times[\mathrm{m}]+j \omega(l) \times[\mathrm{c}]+[\mathrm{k}]
$$

where $(l)$ is length, which varies from 1 to $f$. The value of $f$ is between $250 \mathrm{~Hz}$ and $8000 \mathrm{~Hz}$.

Table 1. Mass and stiffness values in the discrete mass-spring model.

\begin{tabular}{lrlc}
\hline \multicolumn{2}{c}{ Mass (mg) } & \multicolumn{2}{c}{ Stiffness $\mathbf{( N / \mathbf { m } )}$} \\
\hline M1 & 1.55 & K1 & 1175.00 \\
M2 & 2.70 & K2 & $20,001.00$ \\
M3 & 4.00 & K3 & 9474.00 \\
M4 & 4.00 & K5 & $1,000,017.00$ \\
M5 & 1.78 & K6 & 167.00 \\
M6 & 25.50 & K8 & 623.00 \\
\hline
\end{tabular}

Source: Feng and Gan (2004).

Table 2. Damping values in the discrete mass-spring model.

\begin{tabular}{cc}
\hline Damping & Values $\mathbf{( N s / m )}$ \\
\hline C1 & 0.00007 \\
C2 & 0.5 \\
C3 & 1.74 \\
C4 & 0.122 \\
C5 & 0.0216 \\
C6 & 0.00036 \\
C7 & 0.02 \\
C8 & 0.00004 \\
C9 & 0.1 \\
C10 & 0.1 \\
\hline
\end{tabular}

Source: Feng and Gan (2004).
A force equivalent to $90 \mathrm{~dB}$ (SPL) was applied to this system. To obtain the force in Newtons $(\mathrm{N})$ from the intensity in decibels $(\mathrm{dB})$, we used Equation 12 to convert the $90 \mathrm{~dB}$ into sound pressure. Then, the sound pressure value was substituted in Equation 13 to yield the force in $\mathrm{N}$.

$\mathrm{dB}=20 \log \left(\frac{\mathrm{P}}{P_{0}}\right)$

$P=\frac{F}{A}$

$$
\begin{aligned}
& P_{0}=2 \times 10^{-5} \mathrm{~N} / \mathrm{m}^{2} \\
& \mathrm{~F}=\text { Force }(\mathrm{N}) \\
& \mathrm{A}=\text { Area }\left(\mathrm{m}^{2}\right) \\
& \mathrm{P}=\text { Pressure }\left(\mathrm{N} / \mathrm{m}^{2}\right)
\end{aligned}
$$

Equation 13 leads to the force in $(\mathrm{N})$ based on the surface area of the tympanic membrane. In the literature, the total surface area of the tympanic membrane is considered to be $85 \mathrm{~mm}^{2}$. However, only approximately $56 \mathrm{~mm}^{2}$ of the total surface has motility (Costa, 2008). For that reason, surface area of $56 \mathrm{~mm}^{2}$ was considered.

The system of equations described earlier was plotted using MATLAB. The displacement of the stapes in normal conditions and with increased stapedial annular ligament stiffness and stapes mass was obtained.

To compare the results of the application of a $90 \mathrm{~dB}(\mathrm{SPL})$ force (sound pressure level) with the audiometric test results, which employs $\mathrm{dB}(\mathrm{HL})$ (hearing level), a correction was made for each octave 
band. The filters $\mathrm{dB}(\mathrm{SPL})$ or $\mathrm{dB}$ (linear) correspond to the distribution of sound energy as a function of the frequency of the measured noise, while $\mathrm{dB}(\mathrm{HL})$ is intended to approximate the response of the auditory system to the measured noise (Bistafa, 2006).

\section{Results}

Using a discrete mass-spring model capable of representing the auditory system, the characteristic features of otosclerosis was considered, consistent with clinical and audiological findings. The former include progressive hearing loss, tinnitus, and vertigo, or a combination of these depending on the disease stage (Menger and Tange, 2003). The latter are marked by conductive hearing loss, initially for the low frequencies, that progresses to compromise the subsequent frequencies. As bone resorption and remodeling worsen, the disease eventually compromises also the high frequencies (Brookler, 2008; Hungria, 1988).

Initially, the applied force equivalent to $90 \mathrm{~dB}(\mathrm{SPL})$ was converted for each octave band - which ranged between $250 \mathrm{~Hz}$ and $8000 \mathrm{~Hz}$ - into $\mathrm{dB}(\mathrm{HL})$. Except for the $250 \mathrm{~Hz}$ octave band, it was found that the two spectra had similar values; therefore, the results of the study using a force in $\mathrm{dB}(\mathrm{SPL})$ could be compared with the audiometric test results, as illustrated in Figure 3.

In the present discrete mass-spring model of the auditory system, the normal displacement of the stapes was simulated, as well as displacements after 10-fold and 100-fold increases in stapedial annular ligament stiffness. Stapedial displacement after a 5-fold increase in the mass of the stapes was also simulated. Mass and stiffness changes are the clinical parameters that can be directly related to the presence of otosclerosis.

Figures 4, 5, and 6 represent displacements of the stapes with alterations that are typical of otosclerosis. For the lower frequencies (i.e., below $1500 \mathrm{~Hz}$ ), the percent difference in stapedial displacement was inversely proportional to the increase in stiffness. In other words, when stiffness was augmented by 10-fold, stapes displacement was approximately 10 times less. For the higher frequencies (above $1500 \mathrm{~Hz}$ ), the displacement of the stapes decreased linearly at a rate of approximately 10 -fold per octave. With the increase in stapes mass, however, there was no significant variation in stapes displacement at the lower frequencies. In the higher frequencies, stapes displacement declined linearly until a maximal difference of $0.5 \times 10^{-10} \mathrm{~m}$ was reached, at $8000 \mathrm{~Hz}$.

The normal displacement of the stapes was $10^{-8} \mathrm{~m}$, $10^{-9} \mathrm{~m}$, and $10^{-10} \mathrm{~m}$, respectively, for the frequencies $250-2000 \mathrm{~Hz}, 4000 \mathrm{~Hz}$, and $8000 \mathrm{~Hz}$. These results are comparable to those found in the literature for normal stapedial displacement (Feng and Gan, 2002, 2004; Gan et al., 2007, 2010; Huber et al., 2003; Sun et al., 2002). However, the normal stapes displacement

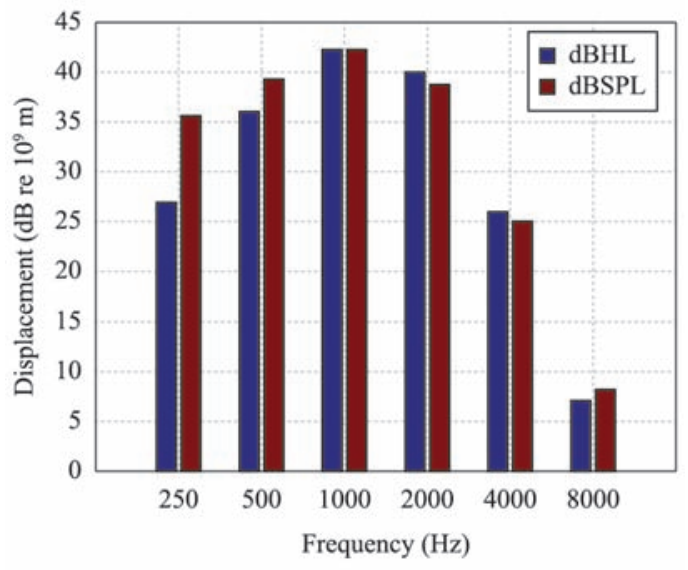

Figure 3. Spectrum in octave bands with sound pressure levels in $\mathrm{dBHL}$ and $\mathrm{dBSPL}$ ( $\mathrm{dB}$ relative to $10^{-9} \mathrm{~m}$ ).

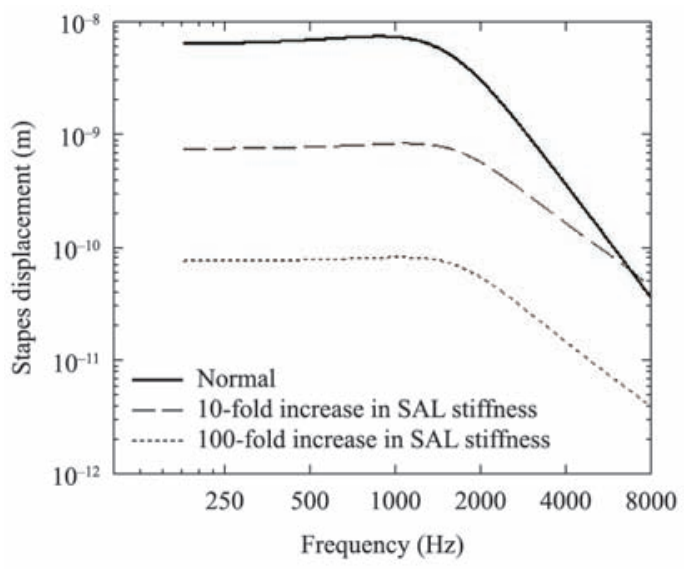

Figure 4. Normal displacement of the stapes and displacements after 10-fold and 100-fold increases in stapedial annular ligament (SAL) stiffness.

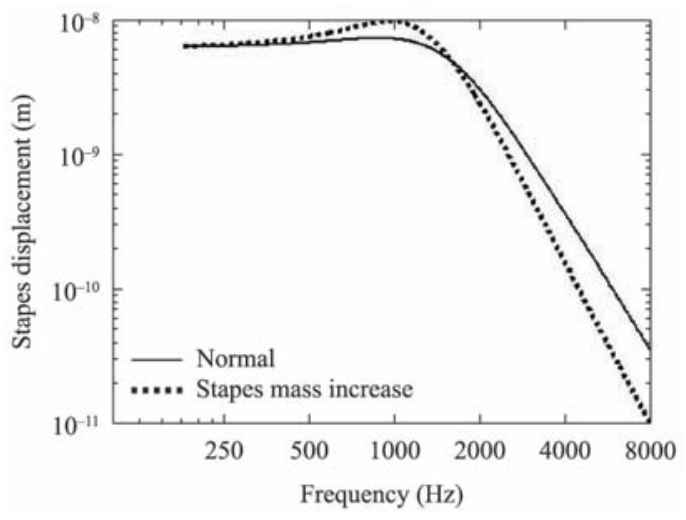

Figure 5. Normal displacement of the stapes and displacement after a 5-fold stapedial mass increase. 


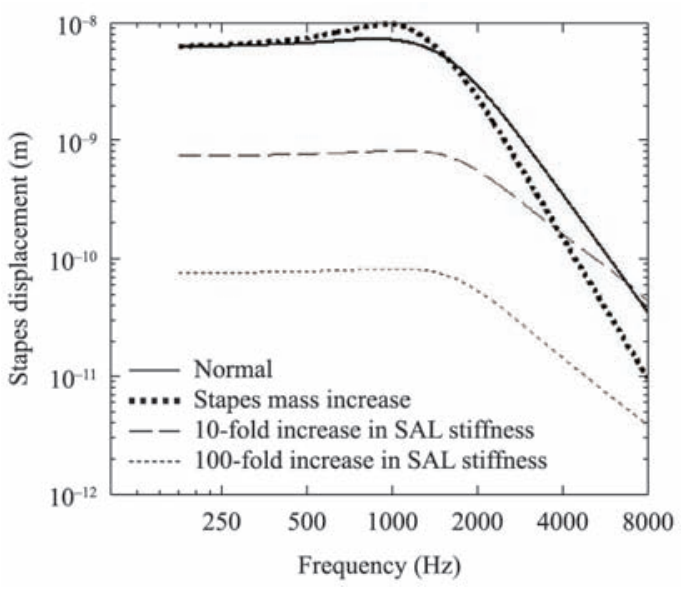

Figure 6. Normal displacement of the stapes and displacements after stapedial annular ligament (SAL) stiffness and stapedial mass increases.

in other studies (which adopted 3-D finite element modeling) was slightly greater and/or smaller (of the order of $\sim 1 \times 10^{-10} \mathrm{~m}$ ) (Dai et al., 2007; Gan et al., 2004; Liu et al., 2009), depending on the frequency range considered. A difference of up to $12.5 \%$ was noted in the range $100-8000 \mathrm{~Hz}$ between the results of 3 -D modeling reported in the literature and those of the discrete model presented herein. This difference in stapes displacement is small, considering the difference in methods among the studies.

\section{Discussion}

There is a paucity of articles reporting otosclerosis simulation, which is due to the difficulty in producing auditory system alterations consistent with the clinical findings of the disease. Our study was aimed at simulating the typical changes caused by otosclerosis using parameters from the literature, in order to better understand the impact of those changes on the different stages of the disease and to be able to contribute to future, more efficacious treatments.

The otosclerotic changes induce increased stiffness of the stapedial annular ligament, which can range from 10 to 100 times its normal value (Feng and Gan, 2004; Huber et al., 2003). They also lead to an increase in stapes mass, as evidenced by a 5 -fold increment in the cell volume of the otosclerotic tissue (Frost, 1962). With the progression of the disease, new areas of bone tissue formation are found, which occur first in the otic capsule and may then extend into the oval window niche and stapes, and are rarely found in the malleus and incus (Beales, 1987; Hungria, 1988; Iyer and Gristwood, 1984).

Whatever the nature of the hearing loss, it can hinder communication, impact daily work activities, and even prevent an individual from listening to music (Albernaz, 2008). Therefore, any intervention towards a better understanding of the mechanisms of hearing loss and potential improvements is of extreme importance (Albernaz, 2008). These facts justify the study of otosclerosis, a disease that causes hearing loss, using a biomechanical model to investigate how certain changes that develop in otosclerosis can impact hearing and, consequently, the social interaction of individuals.

In the present study, a discrete mass-spring model was used to simulate the behavior of the normal and otosclerotic auditory system. In the literature, few articles can be found concerning the use of this type of model to study the auditory system in normal and otosclerotic conditions (Feng and Gan, 2002, 2004). Most of the published studies developed a 3-D model using the finite element method (Dai et al., 2007; Feng and Gan, 2002; Gan et al., 2004, 2007, 2010; Huber et al., 2003; Liu et al., 2009; Sun et al., 2002; Zhao et al., 2009). Regarding simulations of auditory system pathologies, the number of published studies using finite element modeling is smaller (Dai et al., 2007; Huber et al., 2003; Liu et al., 2009; Zhao et al., 2010), and there are even fewer reports on otosclerosis simulation (Huber et al., 2003). However, there are studies that merely mention otosclerosis (Garbe et al., 2010; Kelly et al., 2003).

In the model developed for the present study, a force equivalent to $90 \mathrm{~dB}(\mathrm{SPL})$ was applied to the tympanic membrane and normal displacement of the stapes was noted between $250 \mathrm{~Hz}$ and $8000 \mathrm{~Hz}$, as this range encompasses the frequencies assessed in audiometry. Between $250 \mathrm{~Hz}$ and $2000 \mathrm{~Hz}$, the normal displacement of the stapes was $10^{-8} \mathrm{~m}$; at $4000 \mathrm{~Hz}$, displacement was $10^{-9} \mathrm{~m}$, and at $8000 \mathrm{~Hz}, 10^{-10} \mathrm{~m}$. These results are similar to those reported in the literature (Feng and Gan, 2002, 2004; Gan et al., 2007, 2010; Huber et al., 2003; Sun et al., 2002). However, the normal stapes displacement values found in other studies were slightly greater compared to our study (Dai et al., 2007; Gan et al., 2004; Liu et al., 2009). Probably, this small difference in displacement was due to the geometric models adopted in those studies.

Otosclerosis simulation, in this study, involved an increase in the stiffness of the stapedial annular ligament by 10 -fold and 100 -fold produced by a $90 \mathrm{~dB}(\mathrm{SPL})$ force exerted on the tympanic membrane, which resulted - in both cases-in stapes displacement at the lower frequencies up to $1000 \mathrm{~Hz}$. This result is in line with the findings reported in the literature (Feng and Gan, 2004; Huber et al., 2003).

In addition to increased stapedial annular ligament stiffness, abnormal bony tissue formation is known 
to occur in otosclerosis (Brookler, 2008; Frost, 1962; Hungria, 1988; Miller and Schein, 2005; Min et al., 2010; Vicente et al., 2004). It is also known that the second most commonly affected site is the oval window area and the stapes footplate (Beales, 1987). Thus, our mass-spring model simulated a 5 -fold increase in stapedial mass, based on the literature (Frost, 1962), and the influence of this parameter on the reduction of stapedial displacement was noted only at the higher frequencies, that is, above $2000 \mathrm{~Hz}$ (Figure 5).

The results of these simulations showed that the reduction in stapedial displacements at certain frequencies could be related to the hearing losses observed in audiological tests according to the stage of otosclerosis.

At the early stages of otosclerosis, which typically affects young individuals, the audiogram shows a hearing loss for low-pitched sounds, reflected in an ascending audiometric curve in grade I disease, and the onset of hearing loss for high-pitched sounds as evidenced by the horizontal audiometric curve in grade II otosclerosis (Hungria, 1988). With the present model, it was noted that increasing the stiffness of the stapedial annular ligament resulted in reduced stapes displacement in the lower frequencies and the inferior range of the high frequencies up to $1000 \mathrm{~Hz}$. These results make it possible to predict that increased stapedial annular ligament stiffness is associated with the early stages of the disease, as previously reported (Feng and Gan, 2004; Rocha, 1994). Speech audiometry shows good speech discrimination in grade I and a slight decrease in speech discrimination in grade II (Hungria, 1988). However, an individual is unlikely to manifest any auditory complaint, since the loss of low-pitched sounds accounts for only $5 \%$ of speech intelligibility (Russo, 2009).

At the most advanced stages of the disease, grades III and IV, audiological tests reveal a descending audiometric curve, with hearing loss for high-pitched sounds or even a lack of response for those sounds (Hungria, 1988). Further, there is overgrowth of bone tissue- initially in the otic capsule, which may progress further and extend to the oval window and stapes. This process is rarely found in the other ear ossicles (Beales, 1987; Hungria, 1988; Iyer and Gristwood, 1984). In our discrete mass-spring model of the auditory system, simulating increased stapedial mass resulted in reduced displacement of the stapes only at the higher frequencies (above $2000 \mathrm{~Hz}$ ), as expected for the late stages of the disease. The overgrowth of bony tissue is probably associated with the more advanced stages of the disease, as reported qualitatively in the literature (Frost, 1962; Hungria, 1988; Miller and Schein, 2005; Min et al., 2010;
Palacius and Valvassori, 2001; Vicente et al., 2004). Speech audiometry shows a marked decline in speech discrimination (Hungria, 1988); consequently, the individual complains of difficulties in understanding what is spoken, even with great intensity, particularly in the case of losses around $90 \mathrm{~dB}$ (Albernaz, 2008). This occurs due to the fact that the significant hearing loss for high-pitched sounds from $1000 \mathrm{~Hz}$ accounts for $60 \%$ of speech intelligibility (Russo, 2009).

The discrete mass-spring model of the ear contributed to an enhanced understanding of how the structures affected by otosclerosis influence hearing, and how they relate to the different grades of the disease. When investigating the altered parameters in otosclerosis, it was possible to predict both quantitatively and qualitatively, based on the discrete mass-spring model, the influence of stapedial annular ligament stiffness (Dai et al., 2009; Feng and Gan, 2004; Huber et al., 2003; Min et al., 2010) at the early stages and the influence of increased stapedial mass (Beales, 1987; Brookler, 2008; Frost, 1962; Hungria, 1988; Iyer and Gristwood, 1984; Miller and Schein et al., 2005; Min et al., 2010; Vicente et al., 2004) at the advanced stages, thereby corroborating the qualitative data already reported in the literature.

Despite the limitations of this model, considering that it is one-dimensional and constituted by masses and springs that do not accurately portray the geometry of the ear, it was found that it was capable of defining and relating the different parameters of otosclerosis to the different stages of otosclerosis. Thus, imaging studies in individuals with otosclerosis showing bony tissue overgrowth in the otic capsule, the oval window, or the stapes, can indicate advancing disease and predict the patient's prognosis, as well as serve as an adjuvant in the investigation and treatment of the patient.

Furthermore, considering that increased stapedial annular ligament stiffness is suggestive of early stage otosclerosis—as shown in the present study —and that the disease is rarely symptomatic at this point, the inclusion of stapedial annular ligament status assessment in the audiological tests is justified. The immittance test includes the stapedial reflex test, which measures stapedial muscle contraction when strongly stimulated. We propose that this investigation should also be conducted for the stapedial annular ligament in order to assist in the early diagnosis of otosclerosis, a disease that affects between $0.5 \%$ and $1 \%$ of the population, and presents bilaterally in $70 \%$ to $85 \%$ of cases (Testa et al., 2002).

The early diagnosis of changes in the stapedial annular ligament can have a positive impact on sound transmission in the middle ear, as shown in previous 
studies (Feng and Gan, 2004; Huber et al., 2003). Currently, there is no test to assess the stapedial annular ligament function. Therefore, research aimed at devising diagnostic tests of stapedial annular ligament compromise is critical to allow early interventions regarding the hearing losses deriving from such alterations.

Overall, the model described in this paper showed that increased stiffness of the stapedial annular ligament gives rise to reduced stapedial displacement at the lower frequencies, which is consistent with the early audiometric findings in otosclerosis. The increase in bony tissue mass caused decreased displacement of the stapes at the higher frequencies, which can also be noted in the audiometric configuration of individuals in a more advanced stage of otosclerosis.

The present study showed the important influence of the stapedial annular ligament in the transmission of the sound wave through the middle ear, which warrants further studies in order to find ways to include functional diagnosis of the stapedial annular ligament in audiological tests to enable the early detection of hearing losses.

\section{Acknowledgments}

The authors are grateful to the Brazilian funding agency Coordenação de Aperfeiçoamento de Pessoal de Nível Superior (CAPES).

\section{References}

Albernaz PLM. Quem ouve bem vive melhor: um livro para pessoas com problemas de audição e seus familiares. São Paulo: MG Editores; 2008.

Beales PH. In: Kerr AG, Booth JB. Scott-Brown's disease of ear, nose and throat. 5th ed. London: Butterworth; 1987.

Bertachini L, Gonçalves MJ. Comunicação na terceira idade. Mundo Saúde. 2002; 26(4):483-9.

Bistafa SR. Acústica aplicada ao controle do ruído. São Paulo: Edgard Blucher; 2006. 380 p.

Brookler KH. Clinical findings in a patient with aural fullness. Ear, Nose \& Throat Journal. 2008; 87(2):74-5. PMid:18437924

Costa FG. Estudo biomecânico do ouvido médio [tese]. Porto: Universidade do Porto; 2008.

Dai C, Chenga T, Wood MW, Gan RZ. Fixation and detachment of superior and anterior malleolar ligaments in human middle ear: experiment and modeling. Hearing Research. 2007; 230(1-2):24-33. PMid:17517484 PMCid:PMC2039917. http://dx.doi.org/10.1016/j. heares.2007.03.006

Dai C, Li W, Gan RZ. Change of cochlear mechanics in acute otitis media and otitis media with effusion. In: Midwinter
Meeting; 2009; Baltimore. New Jersey: Association for Research in Otolaryngology; 2009. p. 984. v. 33.

Feng B, Gan RZ. A lumped-parameter mechanical model of human ear for sound transmission. In: Proceedings of the 2nd Joint Conference; 2002; Texas, USA.

Feng B, Gan RZ. Lumped parametric model of the human ear for sound transmission. Biomechanics and modeling in mechanobiology. 2004; 3(1):33-47. PMid:15300453. http:// dx.doi.org/10.1007/s10237-004-0044-9

Frost HM. Observations on the fundamental nature of otosclerosis. In: Schuknecht H. Otosclerosis. Boston: Little, Brown and Company; 1962.

Garbe C, Gentil, F, Parente M, Martins P, Ferreira AJM, Jorge RN. Dynamic analysis of the biomechanic behavior of the middle ear and tympanic membrane through the application of the finite element method. Latin American Journal of Telehealth. 2010; 2(1):78-89.

Gan RZ, Feng B, Sun Q. Three-dimensional finite element modeling of human ear for sound transmission. Annals of Biomedical Engineering. 2004; 32(6):84759. PMid:15255215. http://dx.doi.org/10.1023/ B:ABME.0000030260.22737.53

Gan RZ, Reeves BP, Wang X. Modeling of sound transmission from ear canal to cochlea. Annals of Biomedical Engineering. 2007; 35(12):2180-95. PMid:17882549. http://dx.doi. org/10.1007/s10439-007-9366-y

Gan RZ, Dai C, Wang X, Nakmali D, Wood MW. A totally implantable hearing system: design and function characterization in 3D computational model and temporal bones. Hearing Research. 2010; 263(1-2):138-44. PMid:19772909. http://dx.doi.org/10.1016/j. heares.2009.09.003

Hungria H. Otorrinolaringologia. 8. ed. Rio de Janeiro: Guanabara Koogan; 1988.

Huber A, Koike T, Nandapalan V, Wada H, Fisch U. Fixation of the anterior mallear ligament: diagnosis and consequence for hearing results in stapes surgery. The Annals of Otolology, Rhinology and Laryngology. 2003; 112(4)348-55. PMid:12731630

Iyer PV, Gristwood RE. Histopathology of the stapes in otosclerosis. Pathology. 1984; 16(1):30-8. http://dx.doi. org/10.3109/00313028409067908

Kelly DJ, Prendergast PJ, Blayney W. The effect of prosthesis design on vibration of the reconstructed ossicular chain: a comparative finite element analysis of four prostheses. Otology \& Neurotology. 2003; 24(1):11-9. http://dx.doi. org/10.1097/00129492-200301000-00004

Koike T, Wada H, Kobayashi T. Modeling of the human middle ear using the finite-element method. The Journal of the Acoustic Society of America. 2002; 111(3):1306-17. http://dx.doi.org/10.1121/1.1451073

Liu Y, Li S, Sun X. Numerical analysis of ossicular chain lesion of human ear. Acta Mechanica Sinica. 2009; 25(2):2417. http://dx.doi.org/10.1007/s10409-008-0206-6

Menger DJ, Tange RA. The aetiology of otosclerosis: a review of the literature. Clinical Otolaryngology and Allied 
Sciences. 2003; 28(2):112-20. http://dx.doi.org/10.1046/ j.1365-2273.2003.00675.x

Miller MH, Schein JD. Selected complex auditory disorders. Journal of Rehabilitation Research \& Development. 2005; 42(4):1-8. PMid:16470461. http://dx.doi.org/10.1682/ JRRD.2004.10.0136

Min J, Chung W, Lee WY, Cho YS, Hong SH, Kim HJ, Lee HS. Otosclerosis: incidence of positive findings on temporal bone computed tomography (TBCT) and audiometric correlation in Korean patients. Auris Nasus Larynx. 2010; 37(1):23-8. PMid:19539438. http://dx.doi.org/10.1016/j. anl.2009.04.010

Palacius E, Valvassori G. Coclear and fenestral otosclerosis. Ear, Nose \& Throat Journal. 2001; 80(7):440.

Rocha RM. Tratamento cirúrgico da otosclerose. In: Lopes Filho O, Campos CAH. Tratado de otorrinolaringologia. São Paulo: Roca; 1994.

Roslyn-Jensen AMA. Importância do diagnóstico precoce na deficiência auditiva. In: Ferreira LP. Tratado de fonoaudiologia. São Paulo: Roca; 1996. p. 297-309.
Russo FA. Towards a functional hearing test for musicians: the probe tone method. In: Chasin M, editor. Hearing loss in musicians. San Diego: Plural Publishing; 2009. p. 145-52.

Sun Q, Gan RZ, Chang KH, Dormer KJ. Computerintegrated finite element modeling of human middle ear. Biomechanics and Modeling in Mechanobiology. 2002; 1(2):109-22. PMid:14595544. http://dx.doi.org/10.1007/ s10237-002-0014-z

Testa JRG, Millas I, Vuono IM, Neto MELRBV, Lobato MF. Otosclerose: resultados de estapedotomias. Revista Brasileira de Otorrinolaringologia. 2002; 68(2):251-3. http:// dx.doi.org/10.1590/S0034-72992002000200015

Vicente AO, Penido NO, Yamashita HK, Albernaz M. Tomografia computadorizada no diagnóstico da otoscleros eretrofenestral. Revista Brasileira de Otorrinolaringologia. 2004; 70(1):74-82.

Zemlin WR. Princípios de anatomia e fisiologia em fonoaudiologia. Artmed. 4. ed. São Paulo; 2005.

Zhao F, Koike T, Wang J, Sienz H, Meredith R. Finite element analysis of the middle ear transfer functions and related pathologies. Medical Engineering and Physics. 2009; 31(8):907-16. PMid:19643654. http://dx.doi.org/10.1016/j. medengphy.2009.06.009

\section{Authors \\ Lygia Bueno Fragoso*, Alessandra Terra Vasconcelos Rabelo, Rafaella Cristina Oliveira \\ Biomechanical Engineering Laboratory - Mecbio, Department of Structural Engineering, School of Engineering, Universidade Federal de Minas Gerais - UFMG, Av. Antônio Carlos, 6627, Pampulha, CEP 31270-901, Belo Horizonte, MG, Brazil}

\section{Max de Castro Magalhães, Estevam Barbosa de Las Casas}

Department of Structural Engineering, School of Engineering, Universidade Federal de Minas Gerais - UFMG, Belo Horizonte, MG, Brazil

\section{Juliana Nunes Santos}

Department of Speech-Language Pathology and Audiology, School of Medicine, Universidade Federal de Minas Gerais UFMG, Belo Horizonte, MG, Brazil 